Ten short, interspersed essays treat specific biological, ethical and policy issues in greater depth. For example, an essay on contraception tells how a group of pharmacists that was opposed to filling prescriptions for emergency contraception had claimed that 'morning after' pills cause abortions. In fact, the evidence indicates that such pills act by preventing fertilization. This misinformation may result in preventable, unwanted pregnancies. Similarly, false claims by Vatican officials that the HIV virus can pass through intact condoms may jeopardize the lives of women in regions where AIDS is rampant. "The tragic irony," Gilbert writes, "is that being 'pro-life' regarding the creation of zygotes can make one complicit in the deaths of adult men and women." Other essays address preimplantation genetic diagnosis, umbilical-cord stem cells and eugenics. A 200-word glossary and an accompanying $\mathrm{CD}$ with modifiable figures and PowerPoint presentations for each chapter enhance the book's user-friendliness.

The information that Gilbert presents can largely be found in websites and other books, but nowhere else are the biological facts and the bioethical issues gathered and offered up in such a tastefully concise, beautifully illustrated, engaging and easily consumable format. For example, Biotechnology: Demystifying the Concepts by David Bourgaize and coauthors (Benjamin Cummings, 1999) is an excellent introductory survey of molecular genetics, genetic-engineering technologies and associated ethical and policy issues that addresses in 400 pages what Gilbert discusses in just 34. Similarly, 33 of Gilbert's pages very adequately explain the material covered in the 200-page Human Embryonic Stem Cells by Ann A. Kiessling and Scott Anderson (Jones \& Bartlett, 2003). For cross-disciplinary perspectives on cloning, Michael C. Brannigan's Ethical Issues in Human Cloning (Chatham House, 2000) is very good, but so are the corresponding 16 pages in Gilbert's book. To delve deeper into any of the issues he discusses, one can download non-illustrated, book-length reports by the President's Council on Bioethics (www.bioethics.gov).

With its broad-ranging coverage of embryorelated biotechnologies, Gilbert's book makes an excellent text for high-school and university biology students and for bioethics courses. It also superbly meets the need for an accessible, accurate resource for the biotechnological knowledge needed for informed policymaking. Although lay readers may struggle with some of the science, the book is an important contribution to informed dialogue among citizens from a wide range of educational levels, professions and generations - a first step towards a Prometheus project.

James Bradley is in the Department of Biological Sciences, 331 Funchess Hall, Auburn University, Auburn, Alabama 36849, USA. He is currently writing a book for non-biologists called TwentyFirst Century Biotechnologies and Human Values.

\title{
Tall tales from the deep
}

\section{Singing Whales, Flying Squid and \\ Swimming Cucumbers: The Discovery of \\ Marine Life \\ by Richard Ellis \\ Lyons Press: 2006.288 pp. $\$ 24.95$}

\section{Victor Smetacek}

The news from the sea is depressing these days: depleted fish stocks; turtle, shark and dolphin numbers dwindling at alarming rates; Antarctic blue whales hovering on the brink of extinction; and, looming over all the wanton destruction, are the spectres of pollution, climate change and inexorable acidification. Neptune will be getting very sour. Spreading the bad news is the best one can do these days, hoping that the public at large will realize that the reports warrant red alert.

But not all is gloom and doom. Scientificunderstanding of how oceans and their biota function, and how they interact with the rest of the Earth system to maintain our planet in a habitable state, is growing steadily. But this endeavour of mainstream marine science is more like writing a symphony than painting a big picture. To appreciate the news, one needs to be familiar with the context. Luckily, the sea is also full (or used to be full) of eye-catching animals that appeal to the innate curiosity stimulated by large size and strangeness. Such newsworthy animals continue to be discovered, literally brought to light by the increasing number of searchlights probing the inky vastness. Spreading this type of news is also necessary, as it increases public awareness of the ocean as a fascinating and exciting habitat well worth protecting.

As suggested by its main title, Richard Ellis's book is a collection of short stories on marine animals, selected on the basis of how likely they are to fascinate the reader. The subtitle refers, with few exceptions, to discoveries made by the human eye, and hence on the periphery of mainstream research, which relies on instruments to make its observations. Ellis writes for the public in a breezy, light-hearted style, sometimes struggling to keep up the entertainment level with liberal use of superlatives. He has written many books on good and bad news from the sea, and a glance at some of the titles leaves one wondering how regular readers cope with the repetition. Perhaps the denizens of the deep are indeed so strange that one can write several eye-catching headlines on the same topic.

Ellis is most comfortable writing about big animals and seems out of his depth in the microbial world. He says nothing about the discovery of the archaea, life-forms genetically as distant from bacteria as we are from them. They were first reported from extreme environments but are now being found thriving 
molecules and sulphur. So the recent discovery of an abundance of rhodopsin-bearing bacteria in the open ocean is interesting, but not quite as Earth-shaking as portrayed here.

Similarly, the much-touted independence from solar energy of the peculiar animals that flourish around deep-sea hydrothermal vents overlooks the fact that, although they might not be fed by chlorophyll-driven photosynthesis, they are certainly breathing its waste product, oxygen. Indeed, they are as dependent on chlorophyll as all the other animals living under the Sun, down to the depths of

\section{A right whale, by Richard Ellis.}

\section{the deepest trenches.}

The book provides a healthy mixture of good and bad news from the sea. Hopefully, its portrayal of wondrous worlds inhabited by all manner of huge and strange animals will attract the public and draw muchneeded attention to the ongoing harm being inflicted on the oceans. Serious readers looking for more information may be turned off by the overpowering hyperbole, the eclectic selection of topics, and the giddy leaps from one to another.

Victor Smetacek is professor of bio-oceanography at the University of Bremen and is based at the Alfred Wegener Institute for Polar and Marine Research, 27574 Bremerhaven, Germany.

\section{Seeing the light}

\section{Dan Flavin experimented with fluorescent tubes to create his art.}

\section{Martin Kemp}

The US artist Dan Flavin (1933-96) made his lightworks predominantly using standard fluorescent tubes in five colours: red, yellow, blue, pink and green, as well as shades of white. These prosaic objects seem to provide only a basic means to achieve a limited end. Yet he aimed for nothing less than 'blank magic' - with 'blank' alluding to the plain, even banal, nature of the manufactured components he uses.

The magic lies in the extraordinary elusiveness of colour perception, particularly the effects of ambient colour, after-images, induced colours and complementary contrasts. Flavin's simple but artful arrays of glowing tubes present an extraordinary experimental field for anyone interested in the wonderful subtleties of coloured light and shadows. Yet they are experiments without any apparent theory. He was a true 'empiric' in the ancient sense, trying things to seewhat happened, what worked and what didn't, learning from experience but developing no theory of causes and no system for predicting effects. He was aware of the basic theories of complementary colours (which are different for pigments and for lights) and after-images, but he never dwelt on these or other theoretical aspects of colour in his writings or interviews.

Seemingly, Flavin felt that a set theory would have led to him doing the predictable, with his art, resembling those didactic demonstrations seen in science fairs, museums and exploratoriums. Indeed, at a Flavin exhibition now showing in London, scientists Mark Lythgoe, R. Beau Lotto and Mark Miodownik have devised an informative room of demonstrations of just this kind, looking at phenomena

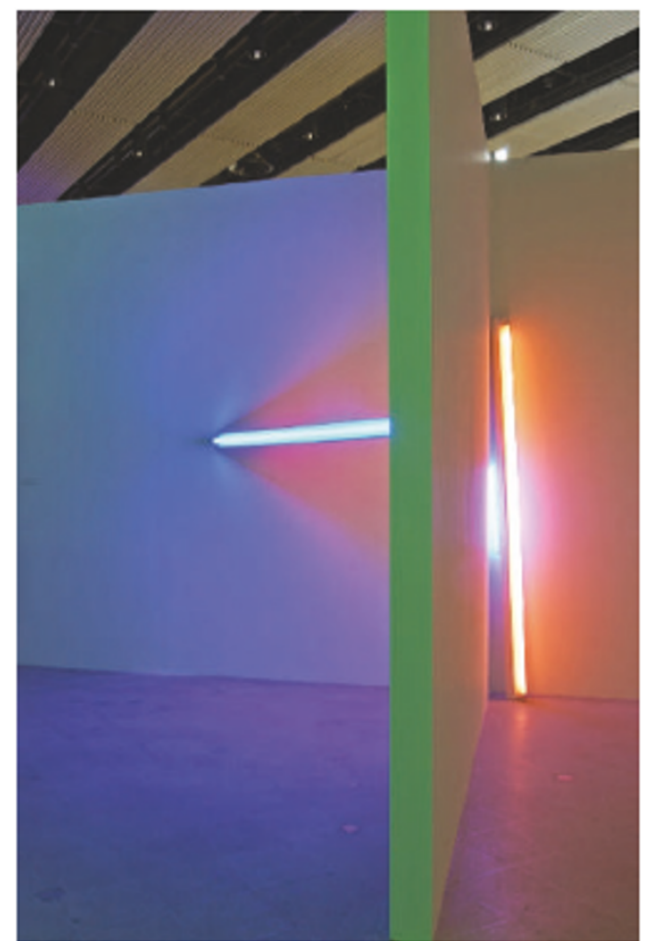

Light on theory: Dan Flavin's experiments with colour were empirical rather than systematic.

of colour and fluorescence.

In experimentally seeking the unknown, rather than merely repeating what is known to work, Flavin behaved like a scientist. But he stopped at his 'blank magic', never trying to propose anything more general beyond the specific experience - and this separates his work from the scientific. He serves up an elusive interpretative field, whereas Lythgoe and his colleagues provide measured demonstrations from which general principles can be adduced.

This is not to say that Flavin's work was intellectually unsophisticated. One of his works is entitled The Nominal Three (for Wm of Odkham). This refers to the medieval philosopher William of Ockham, famous for his philosophical 'razor', who advocated that plurality should not be posited unnecessarily. Ockham rejected the 'universals' favoured by his contemporaries, notably Thomas Aquinas. He argued that the only reality is that of the individuality of particular things, and that universal terms such as 'man' were simply the result of the grouping of similar things by the mind. Ockham's position appealed to Flavin, given his own insistence of the reality of the experience of something, rather than the superior reality of a universal order that supplies predictive rules.

Eventhough Flavinwas raised in an Irish Catholic family in New York, and quoted Ockham, he denied that there was any spiritual dimension in his art. However, moving round the exhibition, bathed in its soft light, with coloured shadows stalking the walls, it is difficult not to think of a church interior suffused by the glow from stained-glass windows.

Miraculous radiance was, traditionally, the manifestation of divine presence. That Flavin's chosen medium of light is immaterial (at least to our unaided senses) lends it a mysterious, even metaphysical, dimension, beyond whathe stated as his intention. His prosaic fluorescent tubes are indeed transposed into the realm of the magical. I suspect that this magic that will be familiar to any scientist who works on colour. 'Dan Flavin: A Retrospective' can be seen at the Hayward Gallery in London until 2 April, before transferring to museums in Paris and then Munich.

MartinKemp is professor of the history of art at the University of Oxford, Oxford OX11PT, UK. owww.hayward.org.uk/flavin 